\title{
Conceptual Framework of Kxpert:Knowledge-Based Information Retrieval for Expert Profiling
}

\author{
Ismail, $\mathbf{S}^{1}$, Ahmad Suhaimi, A.A ${ }^{2}$ \\ ${ }^{1,2}$ Universiti Kuala Lumpur, Malaysian Institute of Information Technology \\ shahrinaz@unikl.edu.my ${ }^{1}$, leyasuhaimi@gmail.com²
}

Article History: Received: 10 November 2020; Revised: 12 January 2021; Accepted: 27 January 2021; Published online: 05 April 2021

\begin{abstract}
With the constant demand for expertise within organisation, especially in boosting the credibility of experts in the organisation, it is a need to bring forth a simple yet effective knowledge-based expert profiling based on information retrieved from credential publication sites. A number of frameworks from previous authors are analysed to propose one sound framework for a case university, to improve its existing research expert database, to make it more efficient in the information retrieval process and knowledge repository technique. Knowledge expertise mapping is proposed to be part of the whole mechanism for the conceptual framework called kXpert in this paper. The choice of credential knowledge sources is highlighted due to the updated information made available on the sites that are based on the published works of the internal experts. Very rare that this information is referred to on daily basis when there is a need to find expertise, thinking that the existing database has it all. The proposed conceptual framework presented in this paper is the work to be completed in the next phase, and can be customised for other organisations, industries and purposes.
\end{abstract}

Keywords:knowledgebase, information retrieval, expert profiling, knowledge expertise mapping

\section{Introduction}

Organisations are in constant demand of people with expertise in explicit and tacit subjects and hence require extensive profiling framework to empower them to find experts in a specific knowledge area. Expert profiling is presented with major challenges in the context of dynamic and evolving knowledge. Consequently, knowledge embedded in such platform is no longer static and continuously evolves, and as knowledge in collaboration platforms changes dynamically, the traditional macro-perspective is insufficient for tracking the evolution of knowledge and expertise.

The current situation implores the need for expert profiling using knowledge-based information retrieval, to prevent the mishap of knowledge loss within the organisation. It is embarrassing to admit yet it is inevitable to say knowledge loss still happens in today's organisations, especially in the small-and-medium-sized enterprises. It is also undeniable that some employees still have the "working in silo" mentality, in which they feel that the work should not be shared else others will take away their best ideas. These two issues have brought upon the difficulties in fulfilling the need to find in-house experts during critical time, especially when everyone is unclear on who is the best person with experience in certain areas. Thinking that one may be an expert of an area does not prove that he or she is especially when admitting that the person is good in something means a huge deal in an organization. This has caused the issue of misconception in experts' fields of expertise. Nevertheless, it is highly important to retain and maintain the expert profiling in an organisation as the need to be innovative is vital to a company's competitive advantage in today's world.

In fulfilling the need to face the issues mentioned above, the main purpose of this research is to assist knowledge seekers to identify the experts within the organisation by mapping knowledge domain to experts. The motivation behind this effort is to provide the "expert seekers" and visitors in search of knowledge experts with access to more accurate and up-to-date profiles that would facilitate better consolidation of expert profiles with seamless aggregation of communities of experts. It is also a motivation to maintain the sustainability of the knowledge by connecting the people with expertise within the organisation. Mitigating the loss of knowledge and experts will address the problem of shortages in skills and talents for the benefits of the people (within and outside of) the organisation. In completing this research companies do not have to reinvent the innovation when all knowledge is well-captured while fully utilizing the knowledge experts in the organisation.

In achieving the main goal of this study, the research objective of this paper is to design a conceptual model of knowledge-based system framework that retrieves credential information from external sources to be delivered to the knowledge seekers.

\section{Related Works}

\subsection{Information Retrieval and Knowledge Management}


A request for information is posed as a question, in whichthe most important service is query answering in knowledge-based information retrieval (Thanos, 2016). Information sources are identified based on the steps in the logical process of responding to the inquiry. The basic idea is to have the clients to express their queries conceptually, and the mapping (i.e. relates to the steps in logical process of responding to them) should be able to translate the request to the system that manages the resources or dataset in knowledgebase (Thanos, 2016).Ingwersen (2002) pointed out that the set of rules and parameters in the knowledgebase are based on the "intentionality and expectation" knowledge as it consists the process of rules and search conditions in information retrieval. It has to have a knowledge map, not only to answer the questions directly but to support the inference mechanism serving as an internal intermediary matching of appropriate resources (Ingwersen, 2002).

The main concern in this aspect is the quality of shared knowledge. There are many differentiators of knowledge in terms of:tacit, implicit and explicit (Davies, 2015);declarative, analytical and procedural (Holsapple\& Joshi, 2002; Hussain\&Ahlam 2020; Talab et al., 2018); local and global (Talab et al., 2018).Past studies showed contradiction among inquiries with respect to the validity of online data and its effect on deals or conduct (Kusumasondjaja et al., 2012). A number of authors suggested that online data is higher in believability than data from other progressively conventional media, in which one of the viewpoints recommended impacting apparent credibility is the message of data quality (Pornpitakpan, 2004).

Knowledge management, on the other hand, is basic for effectively sharing and using people's information at an association level (Bhatt 2001; Dyer \&Hatch, 2006). Knowledge sharing is a piece of information that contributes to knowledge management reciprocally (Kim \&Lee 2006; Lee et al., 2010). Knowledge sharing can support individuals and groups to put together assets and utilise the knowledge that will add to the competitiveness of an organisation (Davenport \&Prusak, 2000; Cabrera \&Cabrera, 2005; Jackson et al., 2006).It is deemed that social trust highly affects the noble purpose of managing knowledge especially in an organisation. Trust has become the system for managing dubious results or future and it is viewed as one of the most dependable indicators for online practices (Gefen, 2000).

It is believed that trust is essential for creating and maintaining relationships to facilitate and foster knowledge sharing, and this would lead to a good quality of knowledge sharing and the knowledge itself (Lee, 2018). Numerous past researchers have contended that social trust is a significant empowering influence for information sharing since it helps individuals in an association to beat obstructions and expectations, in order to begin information sharing exercises more effectively (Butler \& Murphy, 2007). Information exchange and acquisition will be progressively effective when the character of the data source is unveiled (Sussman \&Seigal, 2003).

\subsection{Knowledge-based Expert Profiling Frameworks}

Expert profiling utilises a similar idea for human point affiliation, yet the yield of this errand is a positioned rundown of points that are related to a particular individual (Becerra-Fernandez, 2000). Knowledge seekers can utilise these profiles in framing exact recognitions, clarify misconceptions, and creating inspiration to seek after the knowledge area. Knowledge seekers can profit by master profiles that convey the mix of explicit information, knowledge, innovativeness, and intelligence that characterises the expert performance in their expertise (Sternberg, 2003).

Adopting from the knowledge management concept, a number of frameworks were proposed based on community question answering, in which experts were found based on the activities of answering knowledge seekers' questions in an online community platform. As an example, a framework by Riahi et al. (2012) was to automatically route a newly posted question to an expert user, in which the expert users were detected in the community platform using statistical topic models. On another hand, Pal (2015) proposed a framework that could solve the issue of routing a right question to the right community, hence finding relevant communities for a question. Both of these examples focused on finding experts efficiently, i.e. improvement in terms of time, whereas time is not the only issue in finding the right knowledge expert. In improving these previous works, Neshati et al. (2017) solved the issue of finding future expert by ranking the experts in future based on expertise evidence observed in the current time.

Since this study is specific on certain criteria in finding and profiling knowledge experts, a different approach is focused on. Among the existing frameworks that are relevant to this study are knowledge-based framework (Rodrigues et al., 2015; Zukhi et al, 2020), expert finding (Balog et al., 2012), and expert profiling (Silva \& Ma, 
2017). Overall, these frameworks promise reliable and secure processes that link people in a system to facilitate knowledge seekers in finding the right knowledge experts. The details of these frameworks are as presented in Table 1.

Table 1.Comparison among Expert Profiling Frameworks.

\section{KBF: KNOWLEDBE- BASED FRAMEWORK \\ EXPERT FINDING $\quad$ EXPERT PROFILING}

\begin{tabular}{|c|c|c|c|}
\hline AUTHORS & $\begin{array}{l}\text { Rodrigues } \\
(2015)\end{array}$ & Balog et al. (2012) & Silva \& Ma (2017) \\
\hline \multirow[t]{4}{*}{ PURPOSE } & \multirow{4}{*}{$\begin{array}{l}\text { - Provide reliable } \\
\text { and secure } \\
\text { information, make it } \\
\text { available throughout } \\
\text { organisations' } \\
\text { lifecycle }\end{array}$} & $\begin{array}{l}\text { Identify the problem of } \\
\text { linking humans to expertise areas }\end{array}$ & \multirow{4}{*}{$\begin{array}{l}\text { - Carry out the research using } \\
\text { system-centered perspective } \\
\text { which is similar to document } \\
\text { search }\end{array}$} \\
\hline & & $\begin{array}{l}\text { from a human-centered } \\
\text { perspective }\end{array}$ & \\
\hline & & $\begin{array}{l}\text { - Utilise human knowledge } \\
\text { within an organisation as well as } \\
\text { possible }\end{array}$ & \\
\hline & & $\begin{array}{l}\text { - Assist the expertise seeker to } \\
\text { find the most appropriate expert, } \\
\text { based on the expert's actual } \\
\text { knowledge }\end{array}$ & \\
\hline \multirow[t]{5}{*}{ Processes } & \multirow[t]{5}{*}{$\begin{array}{l}\text { - Identifying, } \\
\text { capturing, evaluating, } \\
\text { retrieving, and } \\
\text { sharing all of an } \\
\text { organisation'sinforma } \\
\text { tion asset }\end{array}$} & $\begin{array}{l}\text { - Map tacit knowledge (help } \\
\text { individuals to develop a better } \\
\text { awareness about which individual } \\
\text { knows what) } \\
\text { - Extend social network by } \\
\text { improving the connections }\end{array}$ & $\begin{array}{l}\text { - Link humans to expertise } \\
\text { areas and identify the best } \\
\text { match between a need for } \\
\text { expertise and the content of } \\
\text { documents associated with } \\
\text { candidate experts }\end{array}$ \\
\hline & & $\begin{array}{l}\text { between people who are } \\
\text { acquainted with one another }\end{array}$ & \multirow{2}{*}{$\begin{array}{l}\text { - Improve expertise search } \\
\text { with more visibility even for } \\
\text { people who did not tag } \\
\text { themselves with the area of } \\
\text { expertise }\end{array}$} \\
\hline & & $\begin{array}{l}\text { - Increase } \\
\text { between people who are not } \\
\text { acquainted }\end{array}$ & \\
\hline & & & $\begin{array}{lr}\text { - Higher } & \text { potential of } \\
\text { accessibility, } & \text { reliability, }\end{array}$ \\
\hline & & & $\begin{array}{l}\text { physical proximity, an } \\
\text { freshness }\end{array}$ \\
\hline
\end{tabular}

The main aim in expert finding framework by Balog et al. (2012)is to connect the knowledge seeker to the sources. This is performed through a source-selection process based on selection criteria determined by the context and the task and information needed, as shown in Figure 1. In comparison, the expert profiling framework by Silva and Ma (2017) starts off with the research and development problem, which this problem is broken down to topics during problem analysis process, and these "expertise topics" are then mapped to the expert candidates available. From the other side of this framework, the expert candidates go through a profiling process that generates individual profiles to be used in the expertise mapping. This framework is shown in Figure 2. 


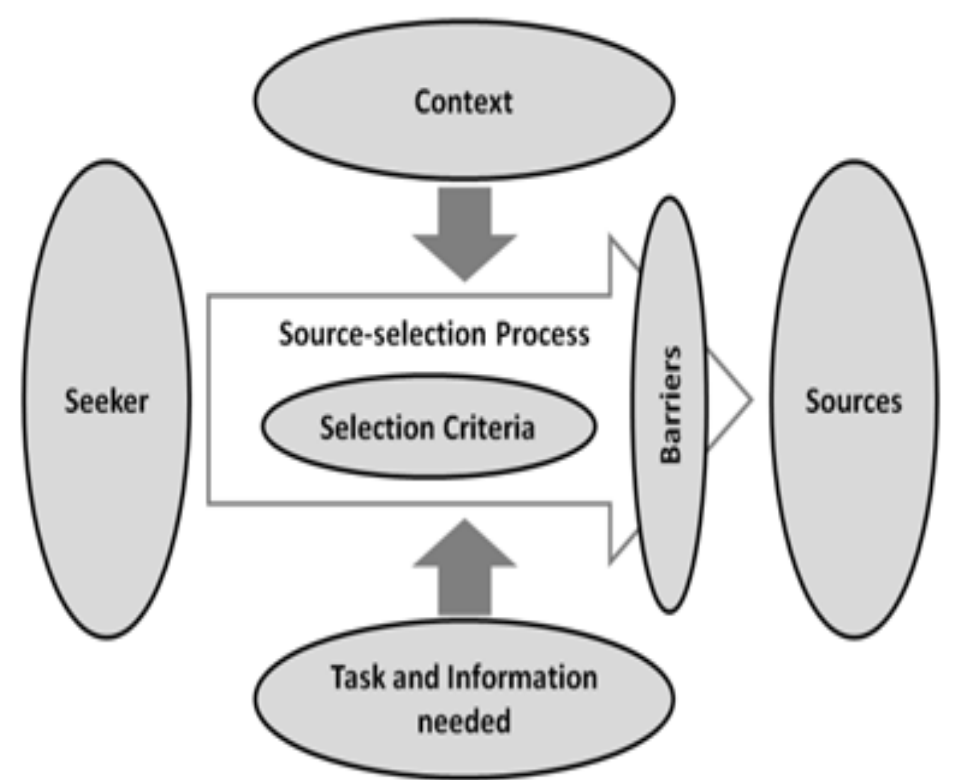

Figure 1.Expert finding framework by Balog et al. (2012)

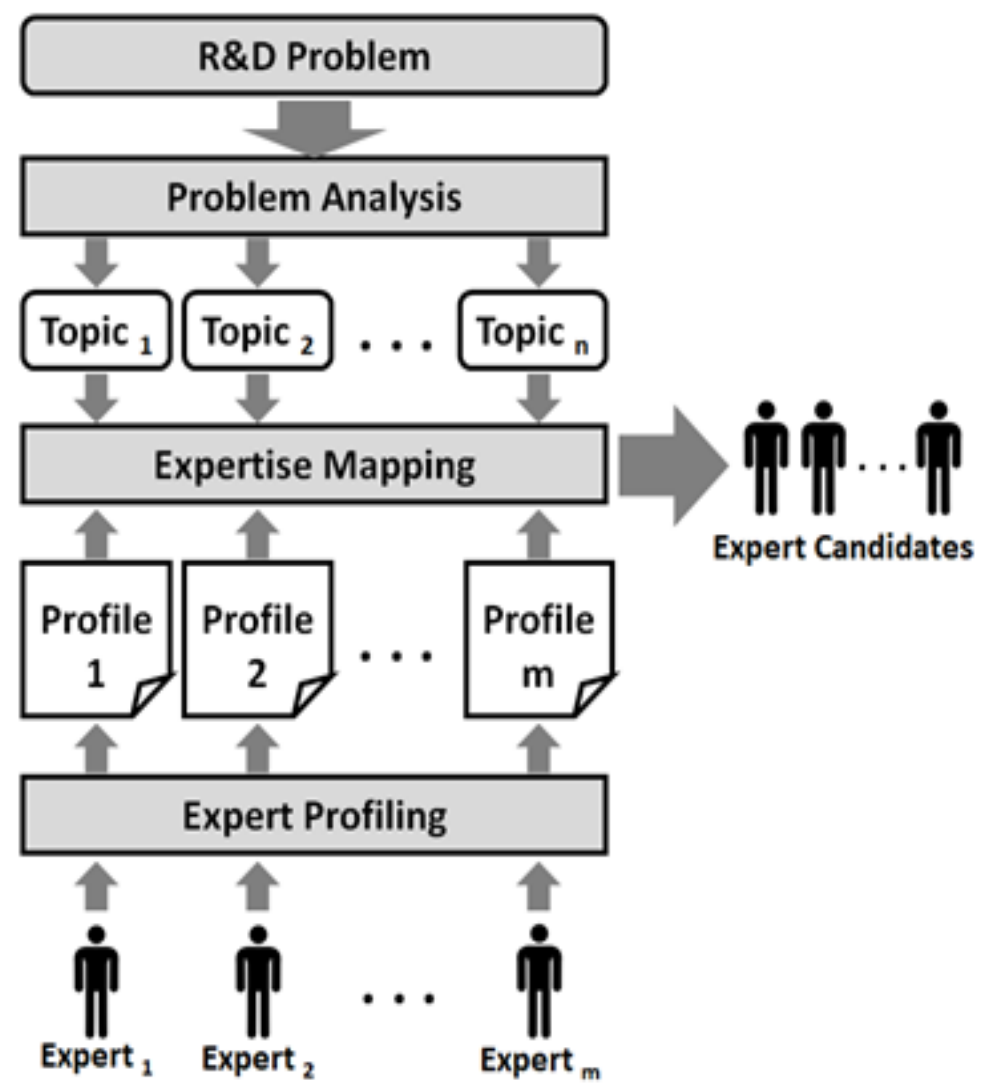

Figure 2.Expert profiling framework by Silva and Ma (2017)

The gist of an expert profiling system is knowledge mapping, which this research is focusing on during the design and development of the proposed framework. Knowledge mapping contributes to open learning where it helps organisation to organise knowledge in several contexts, such as learning design, learning path planning and problem solving, on online learning and distance education (Alexandra \& Simon, 2006). Kim et al. (2003) suggested a technique to develop a knowledge map for an industrial organisation via capturing and demonstrating organisational knowledge. As such, the authors stated that knowledge map is the best tool to represent knowledge in an organisation. Constructing knowledge map assists administrator to build up and enhance training and educational support systems to achieve successful team working and see knowledge relations within and across knowledge areas in organisations (Balaid, 2013). 


\section{Methodology}

This research is based on a case setting of a private university in Malaysia, in which its research expert database needs to be improved in terms of information retrieval mechanism and knowledge repository efficiency. The methodology started off with requirement analysis, which include an interview with a member of the Research and Innovation Section, and literature analysis.

An interview was conducted to gather the insights of the current situation and needs of finding experts within the case university. It is understood that identifying and knowing the internal experts could expedite in many tasks, with most of them related directly to the key performance indicators (KPIs) of the employees within the firm. As an example, the task of verifying the research papers published by the faculty members could facilitate in Malaysia Research Assessment (MyRA) data collection and confirmation, which is vital to the university in strengthening its ranking position in the country. At the same time, internal researchers could benefit from knowing the experts for future research and project collaboration, as well as citing each other's research papers to increase the citation index of the authors within the firm and expert domains. Having said this, the most reliable and significant sources of knowledge experts for the proposed information retrieval system are the Scopus index and Web of Science databases. In current practice, the Scopus index database is often referred to for searching authors under the affiliation of the case university, in which would cause hassle and inefficiency when the number of potential authors in a faculty could reach up to 200 researchers at one time.

Literature analysis and frameworks comparison are performed to produced an insight on the elements to be covered in designing a framework for kXpert. Although there are many frameworks and models on expert profiling in previous works, only a few are found to be closely related to the needs of the case university. As discussed in the previous section, the main frameworks being selected for further analysis in this research are the expert finding (Balog et al., 2012) and expert profiling (Silva \& Ma, 2017), after thorough considerations on other relevant frameworks. Table 2 shows the comparison between these two frameworks, and the considerations taken into account in this study.

Table 2.Comparison among Expert Profiling Frameworks.

\begin{tabular}{|c|c|c|c|}
\hline & EXPERT FINDING & EXPERT PROFILING & CONSIDERATIONS FOR KXPERT \\
\hline INPUT & $\begin{array}{l}\text { - Context, criteria (from } \\
\text { Seeker), task, information }\end{array}$ & - Problem, topic, expert profile & $\begin{array}{l}\text { - Keywords (topics), affiliation of } \\
\text { experts, name (if required for } \\
\text { updates) }\end{array}$ \\
\hline Process & $\begin{array}{l}\text { - Source-selection } \\
\text { process }\end{array}$ & $\begin{array}{l}\text { - Problem analysis, expertise } \\
\text { mapping, profiling of experts }\end{array}$ & $\begin{array}{l}\text { - Search, retrieval, knowledge } \\
\text { expertise mapping }\end{array}$ \\
\hline OUTPUT & $\begin{array}{l}\text { - Selected source (link to } \\
\text { the identified sources) }\end{array}$ & - Experts identification & $\begin{array}{l}\text { - Experts identification with } \\
\text { number of publications on keywords } \\
\text { (topics) }\end{array}$ \\
\hline
\end{tabular}

Based on the interview and literature analysis, researchers or publication authors in most cases depend on the keywords (and publication titles) that they define in their research as their expertise, and these are the two elements that this proposed framework is focusing on as expertise selection criteria. A proposed framework called kXpert is based on the needs to find experts in certain research areas, in which they may not be categorised in standard domain names. The considerations for kXpert mentioned in Table 2 are the basis of the conceptual model proposed in this paper, as covered in the next section.

\section{Conceptual Framework}

The proposed kXpert is a knowledge-based system that maps internal experts to the expertise domains by retrieving information from credential external sources (e.g. Scopus, Web of Science). These two elements are mapped and stored in the knowledgebase or knowledge repository of the organisation. The information and knowledge mapping will be often updated as and when needed or after certain period of time if it is not requested by anyone. The experts' details for the information retrieval are the names and affiliation (i.e. university, campus or faculty). The overall conceptual framework is as shown in Figure 3, with the input, process and output mentioned in Table 2. 


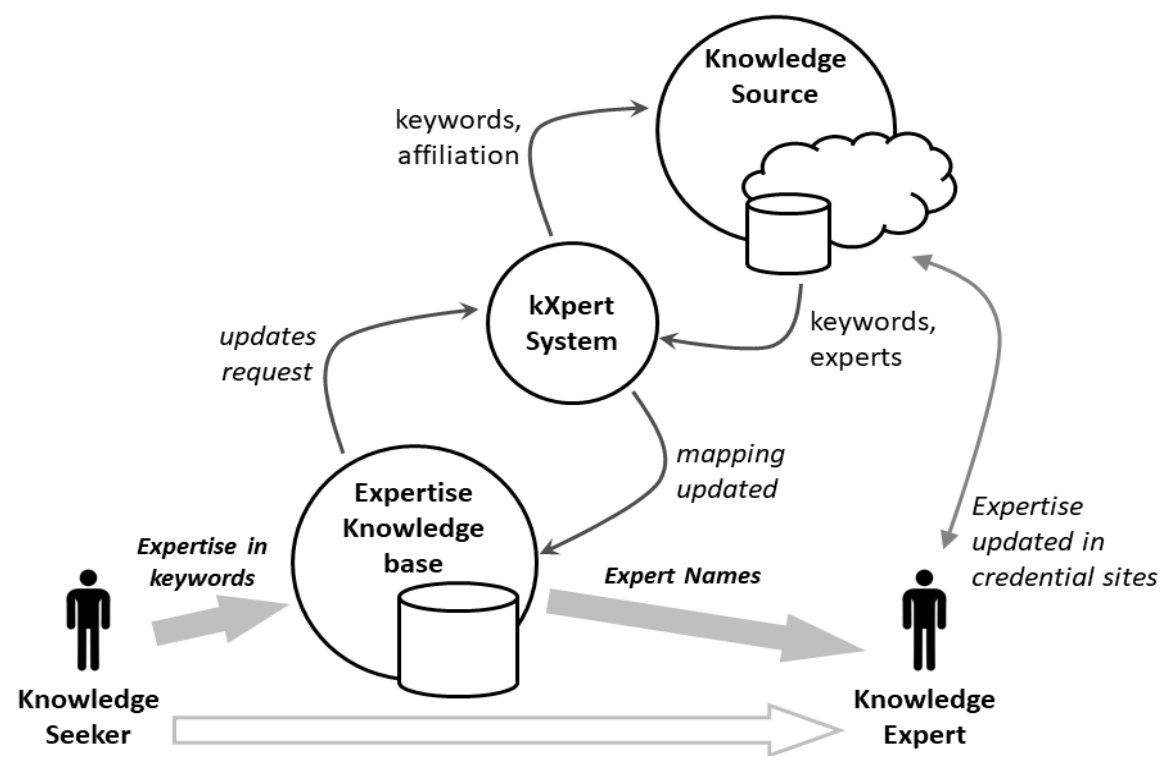

Figure 3.kXpert conceptual framework

The main processes performed by this proposed framework are: the retrieval of expertise in the form of keywords by knowledge seeker; search of keywords based on affiliation name (i.e. university and campus/faculty) in credential site(s); retrieval of search results to be imported to the knowledgebase; knowledge expertise mapping in the knowledgebase; and displaying of results to the knowledge seeker. The results will be customised based on the needs of information details, such as name of experts, affiliated faculty/campus, expertise topics, and number of publications based on the expertise topics (keywords).

\section{Conclusion}

Expert profiling elevates the current standard of knowledge-based information retrieval and help the organisation to organise, convey, and encourage learning results. The outcome of this work would be to show that performance of information retrieval can be improved by the expert profiling approach based on certain simple criteria. The achievement of the objectives of this study will contribute to a useful and effective knowledge-based framework and knowledge map, catered to the needs of mitigating knowledge expertise loss in an organisation.

\section{Acknowledgment}

The authors would like to express appreciation for the support of the sponsors [UniKL Short Term Research Grant Number $=$ str19040].

\section{References}

1. Thanos, C. 2016. A Vision for Open Cyber-Scholarly Infrastructures. Publications, 4, 13.

2. Ingwersen, P. 2002. Information Retrieval Interaction. London: Taylor Graham Publishing.

3. Davies, M. 2015. Knowledge (Explicit, Implicit and Tacit): Philosophical Aspects. In International Encyclopedia of the Social \& Behavioral Sciences (2nd Ed.), Academic Press, 74-90.

4. Holsapple, C.W. and K.D. Joshi. 2002. Knowledge Management: A Threefold Framework. The Information Society, Taylor \& Francis, 18:47-64.

5. Hussain, A., Omar, A.M. (2020). Usability evaluation model for mobile visually impaired applications. International Journal of Interactive Mobile Technologies, 14 (5), pp. 95-107.

6. Talab, A.H., Scholten, V.E. and van Beers, C. 2018. Knowledge Sharing and Open Innovation. Open Innovation and Knowledge Management in Small And Medium Enterprises 3, 117, Chapter 6.

7. Kusumasondjaja, S., T. Shanka and C. Marchegiani. 2012. Credibility of online reviews and initial trust: The roles of reviewer's identity and review valence. Journal of Vacation Marketing, 18: 185-195.

8. Pornpitakpan, C. 2004. The persuasiveness of source credibility: A critical review of five decades' evidence. Journal of Applied Social Psychology, 34:243-281.

9. Bhatt, G.D. 2001. Knowledge management in organisations: Examining the interaction between technologies, techniques and people. Journal of Knowledge Management, 5: 68-75. 
10. Dyer, J.H. and N.W. Hatch. 2006. Relation-specific capabilities and barriers to knowledge transfer: creating advantage through network relationships. Strategic Management Journal, 27:701-719.

11. Kim, S. and H. Lee. 2006. The impact of organizational context and information technology on employee knowledge-sharing capabilities. Public Administration Review, 66:370-385.

12. Lee, P., N. Gillespie, L. Mann and A. Wearing. 2010. Leadership and trust: Their effect on knowledge sharing and team performance. Management Learning, 41:473-91.

13. Davenport, T.H. and L. Prusak. 2000. Working knowledge: how organizations manage what they know. Ubiquity, Article 6.

14. Cabrera, E. F. and A. Cabrera 2005. Fostering knowledge sharing through people management practices. International Journal of Human Resource Management, 16:720-735.

15. Jackson, S.E., C.-H. Chuang, E.E. Harden, Y. Jiang and J.M. Joseph. 2006. Toward developing human resource management systems for knowledge-intensive teamwork. In J. M. Joseph (Ed.), Research in personnel and human resources management, 25, Amsterdam: JAI, 27-70.

16. Gefen, D. 2000. E-commerce: the role of familiarity and trust. Omega. 28:725-737.

17. Lee, J. 2018. The Effects of Knowledge Sharing on Individual Creativity in Higher Education Institutions: Socio-Technical View. Administrative Science, 8.

18. Butler, T. and C. Murphy. 2007. Understanding the design of information technologies for knowledge management in organizations: A pragmatic perspective. Information Systems Journal, 17:143-63.

19. Sussman, S.W. and W.S. Siegel. 2003. Informational influence in organizations: An Integrated approach to knowledge adoption. Information Systems Research, 14:47-65.

20. Becerra-Fernandez, I. 2000. The role of artificial intelligence technologies in the implementation of PeopleFinder knowledge management systems. Knowledge-Based Systems, 13:315-320.

21. Sternberg, R. 2003. What Is an "Expert Student?". Educational Researcher, 32:5-9.

22. Riahi, F., Z. Zolaktaf, M. Shafiei and E. Milios. 2012. Finding expert users in community question answering. Proceedings of the 21st international conference on world wide web: 791-798.

23. Pal, A. 2015. Metrics and algorithms for routing questions to user communities. ACM Transactions on Information and System, 33:1-14:29.

24. Neshati, M., Z. Fallahnejad and H. Beigy. 2017. On dynamicity of expert finding in community question answering. Information Processing \& Management, 53: 1026-1042.

25. Rodrigues, D., R.R. Zaniolo and K.R.L.J.C Branco. 2015. Knowledge-Based Framework: Its specification and new related discussions. Journal of Physics: Conference Series, 633.

26. Balog, K., Y. Fang, M. Rijke, P. Serdyukov and L. Si. 2012. Expertise Retrieval. Foundations and Trends in Information Retrieval, 6:127-256.

27. Silva, T. and J. Ma. 2017. Expert profiling for collaborative innovation: big data perspective. Information Discovery and Delivery, 45:169-180.

28. Okada, A. and S.B. Shum. 2006. Knowledge Mapping with Compendium in Academic Research and Online Education. In 22nd World Conference, International Council of Distance Education, 3-6 Sep 2006, Rio de Janeiro, Brazil.

29. Kim, S., E. Suh and H. Hwang. 2003. Building the knowledge map: An industrial case study. Journal of Knowledge Management.

30. Zukhi, M.Z.M., Hussain, A., Husni, H. (2020). Culturicon design model for social mobile application. International Journal of Interactive Mobile Technologies, 14 (5), pp. 16-31.

31. Balaid, A.S.S., M. Zibarzani and M.Z.AbdRozan. 2013. A Comprehensive Review of Knowledge Mapping Techniques. Journal of Information Systems Research and Innovation, 3:71-76. 